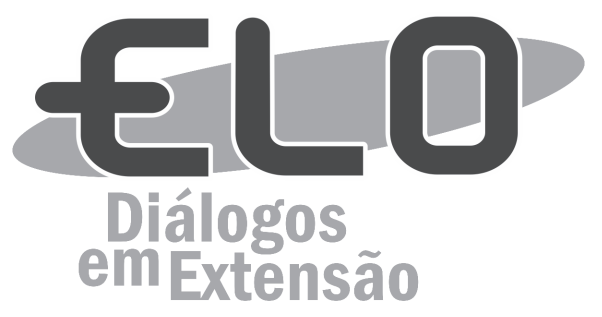

\title{
Quando a extensão alcança a população - PROLINFO: um tredécimo de oportunidades educacionais
}

Vinicius Gomes Pascoal ${ }^{1}$

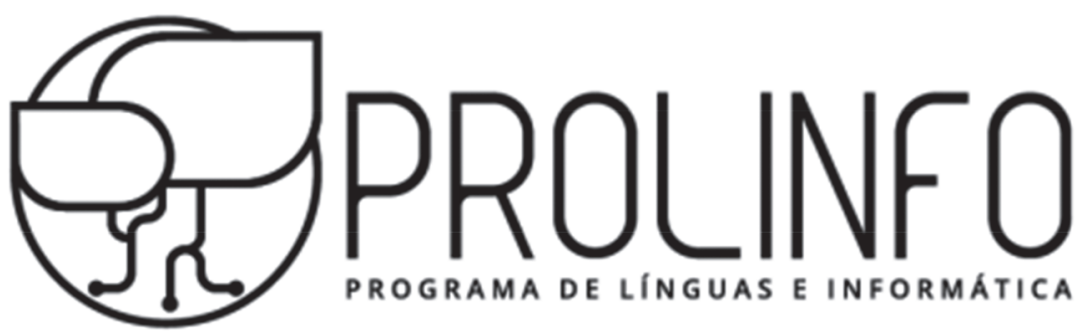

Figura 1 -: PROLINFO-UPE

Criado em 2002 por docentes do curso de Licenciatura em letras: inglês - português e suas literaturas, na UPE Campus Mata Norte, o PROLINFO - Programa de Línguas e Informática - é atualmente o programa de extensão que mais cresce dentro da Universidade de Pernambuco UPE.

É lugar comum que toda universidade é resultado de uma tríade composta por ensino, pesquisa e extensão. Em teoria, o ambiente acadêmico é o espaço no qual o estudo e a pesquisa devem retornar à sociedade em forma de ações de extensão. Essas atividades precisam ser abertas e inclusivas ao público, em resumo, precisam ir muito além dos muros da universidade.

O PROLINFO, além de ser um mecanismo que torna acessível a produção acadêmica à sociedade, é também uma escola de formação de professores. O programa atualmente registra um total de 6.000 estudantes matriculados na capital e em mais cinco cidades de Pernambuco. Para atender essa demanda são necessários aproximadamente cem jovens professores-regentes, estudantes talentosos que são contratados em regime de estágio por meio de seleção pública.

Todas as ações propostas pelo programa são coordenadas por uma equipe gestora composta por cinco professores coordenadores ligados ao IAUPE (Instituto de Apoio à Universidade de Pernambuco), um professor titular da UPE, a quem compete a coordenação geral, e sete colaboradoras de apoio administrativo que trabalham nas secretarias dos polos descentralizados, com distância de $709 \mathrm{~km}$ (Petrolina), 68km (Nazaré da Mata), 228km (Garanhuns), 18km (Camaragibe) e 253km (Arcoverde) da Região Metropolitana do Recife.

O processo de interiorização do PROLINFO foi iniciado em 2013, pelo atual coordenador geral do programa. Para tal façanha, foi necessário instrumentalizar um sistema de recursos humanos

\footnotetext{
É professor e coordenador das atividades de interiorização (Mata Norte, Agreste, São Francisco e Sertão Pernambucano), Avaliação Institucional, RH, Selo Editorial, Flipboard e Instagram do Programa de Línguas e informática da Universidade de Pernambuco - IAUPE - UPE - PROLINFO. É licenciado pela UPE (2011), Especialista em Metodologia da Tradução pela Faculdade Frassinetti do Recife - FAFIRE (2012) e Mestre em Teoria da Literatura pela UFPE (2015). Possui aperfeiçoamento em língua inglesa pela Universidade de Oregon (2015), em filosofia pela Cornell University (2015), em comunicação pela Universidade de Hong Kong (2015), em literatura pela Harvard \& Vanderbilt (2015), em liderança inclusiva pelo Catalyst (2015) e em ciências políticas pela Delft University of Technology, ETH Zürich \& Massachusetts Institute of Technology - MIT (2015). É tradutor (EN-PT) no Twitter Translator Center \& Facebook Translations Team, além de ter integrado o corpo de jurados da Sulake.Inc (Brasil-Finlândia). Endereço: R. Rio Jiquiá, n56, 50.721-310. Recife, PE (81)98764-3457.
} 
organizado de forma digital (RH PROLINFO) no qual os candidatos ${ }^{2}$ são cadastrados e selecionados, em todo estado de Pernambuco, de maneira idônea e transparente.

O processo de formação universitária oferecido aos professores-regentes do PROLINFO é contínuo, inclusivo, multidisciplinar e plural. Com o uso das tecnologias de informação e comunicação, aliado ao uso de videoconferências realizadas nas secretarias do programa espalhadas pelo interior do estado de Pernambuco, a equipe gestora do PROLINFO oferece uma série de programas inovadores aos seus professores em formação. No ano de 2015 foram totalizados 540 horas destinadas à orientação pedagógica (o que equivale a 22 dias ininterruptos dedicados exclusivamente em aperfeiçoar a prática docente).

Há também a oportunidade de formação transdisciplinar, neste ano de 2015 as opções foram os cursos da Fundação Bradesco e da Fundação Lemann, além da plataforma Google Classroom - sendo a primeira instituição educacional no Brasil a utilizar essa ferramenta. Mas não apenas da atividade de docência se ocupa a equipe do PROLINFO, que também atua em eventos culturais, como aconteceu na cobertura da X Bienal Internacional do Livro de Pernambuco e na etapa final da $3^{\text {a }}$ Conferência Nacional da Juventude - CNJ.

O espírito de renovação e evolução são palavras-chave, de uso comum e de ordem, nessa equipe que atualmente projeta a instalação de novos cursos (francês e alemão), a expansão do programa em outros municípios de Pernambuco (Salgueiro e Serra Talhada), a oferta de um curso de pós-graduação em língua inglesa, e a elaboração do PROLINFO EAD, uma parceria com a UPE-PROEC, este último sob execução da mais nova coordenadora na equipe.

Atualmente o corpo discente do PROLINFO é composto por brasileiros e alóctones, assim o programa também oferece cursos de língua portuguesa a estrangeiros residentes no Brasil, cursos institucionais para intercambistas instalados na UPE, curso instrumental para pós-graduandos e cursos preparatórios aos discentes da UPE que realizarão exames de proficiência na língua inglesa e espanhola.

O PROLINFO é um programa constituído, em sua grande maioria, por jovens de 18 a 29 anos e é uma família que se espalha pelo estado de Pernambuco.

\footnotetext{
${ }^{2}$ Em razão da especificidade da língua portuguesa, neste artigo foram adotados os termos no gênero masculino, para facilitar a leitura. O autor, preocupado e engajado com a promoção da igualdade de gênero, reforça que embora alguns termos estejam grafados no masculino, eles referem-se igualmente ao gênero feminino.
} 